\section{Prevalence and Assessment of Depression among Diffuse Idiopathic Skeletal Hyperostosis (DISH) patients}

\section{Abstract}

Background: Depression is most frequent among physical illness. Diffuse Idiopathic Skeletal Hyperostosis is a condition in which several ligaments and entheses become ossified.

Objectives: Assessment of depression and the severity of depression among patients with diffuse idiopathic skeletal hyperostosis, and detection of risk factors.

Methods: patients with diffusive idiopathic skeletal hyperostosis, both genders who have consulted during the study period and given their consent were assessed through sociodemographic and clinical data collection, and PHQ-9 questionnaire for depressive disorders evaluation.

Results: The study investigates 43 patients with diffuse idiopathic skeletal hyperostosis. Prevalence of depression was $62 \%$. Almost $88.88 \%$ of them were moderate to severe depression. Depression significantly associated with age, gender, occupation, life events, and duration of illness.

Conclusion: depression is high in patients with diffuse idiopathic skeletal hyperostosis. Age, gender, occupation, life events, and duration of illness consider as the significant risk factors.

Keywords: Depression; DISH; PHQ-9; Prevalence; Iraq

\section{Shalan Joodah Rhemah Al-Abbudi \author{
Iraq
} \\ Consultant Psychiatrist, F.I.B.M.S.Psych, Imamain Kadhimain Medical City, Baghdad,}

\section{Corresponding author:}

Shalan Joodah Rhemah Al-Abbudi

\section{ફshalanjoodah@gmail.com}

Shalan Joodah Rhemah Al-Abbudi, Consultant Psychiatrist, F.I.B.M.S. Psych, Imamain Kadhimain Medical City, Baghdad, 70131, Iraq.

Citation: Al-Abbudi SJR, (2019) Prevalence and Assessment of Depression among Diffuse Idiopathic Skeletal Hyperostosis (DISH) patients. Clin Psychiatry Vol.4 No.3:12

Received: December 04, 2018; Accepted: January 01, 2019; Published: January 08, 2019

\section{Introduction}

Diffuse idiopathic skeletal hyperostosis (DISH) is a common systemic condition, of prevalence nearly $10 \%$ in those aged $>50$ years [1]. DISH also called as Forestier's disease, described firstly in 1950 by Rotes-Querol and Forestier. DISH is systemic idiopathic disease affecting the axial skeleton characterized by anterolateral spinal ligaments ossification and formation of osteophyte along the whole spines [2]. Decreased mobility and mild backache may be the results of ossification of many ligaments [3]. Thoracic spine usually affected by the disorder. Other joints and spines may be affected. Treatment and diagnosis usually delayed because the majority of patients were asymptomatic [4]. The pathogenesis of DISH was not clear, but other factors like; anatomic, endocrine, metabolic, genetic, toxic, and environmental factors may take part [5]. DISH is a disorder of old age, predominantly males male/female ratios 2:1-7:1 [6]. Physical illness induced mental illnesses usually disturbing to volition, personality disorder, and dementia. Mood disorders were accompanied physical illness, and most frequent is depression. Depression comorbid with physical disorders can be reactive or psychogenic inducted by social situation changes or depression directly results from the medical condition [7]. Characteristic features of depression include loss of interest, sadness, low self-esteem, feelings of guilt, sleep disturbance, changed appetite, poor concentration and tiredness. Depression may be long-lasting cores or recurrent episodes, with impairment of person's daily life function, work and school. Severe depression may end with suicide [8]. Depression diagnosis needs experience and accurate evaluation. Clinical practice and research purposes required tools for screening of depression. Many screening questionnaires are available, with different score thresholds to diagnose depression [9]. The Patient Health Questionnaire 9 (PHQ-9) is valid brief questionnaire [10] that used DSM-IV criteria for diagnosis of depression [11]. PHQ9 can be self-rated, or interviewer-rated and is well validated dual-purpose questionnaire in the US that gives picture of 
depression severity [12], and DSM-IV diagnoses of depressive disorders: major depressive disorder, other depressive disorder and any depressive disorder. Validity of PHQ-9 was done in many countries in view of construct validity, diagnostic accuracy [13], changes sensitivity, responsiveness to treatment [14], internal consistency, test-retest reliability [15] and realistic estimates of population base rates [16].

Assessment of depression and the severity of depression among patients with diffuse idiopathic skeletal hyperostosis, and analysis of the significant sociodemographic and clinical risk factors associated with diffuse idiopathic skeletal hyperostosis patients were the aims of this study.

\section{Methods}

\section{Design and setting}

The current is a cross-sectional study. It was conducted from February 1st, 2015 to 31st August 2018, in the Psychiatry department with cooperation with Rheumatology unit at Imamain Kadhimain Medical City, Baghdad, Iraq.

\section{Study population}

All patients with diffusive idiopathic skeletal hyperostosis (DISH), both genders who have consulted within the time of study and given their agreement to participate were included.

\section{Data collection tools}

Questionnaires were filled by consultant psychiatrist, which included; the collection of sociodemographic and clinical data and PHQ-9 scale. The diagnosis of diffusive idiopathic skeletal hyperostosis (DISH) was based on the clinical findings, radiographic, and biological arguments. The study used the Arabic version of PHQ-9 to identify depression. Face validity process and internal consistency reliability was measured using Cronbach's alpha for the PHQ9, the results was 0.857 [17]. Patient Health Questionnaire (PHQ) is a clinical diagnostic tool that is widely utilized worldwide because it provides a practical in clinic tool to screen for psychological disorders. A PHQ-9 score $\geq 10$ has a sensitivity of $88 \%$ and a specificity of $88 \%$ for major depression [13]. Major depressive disorder diagnosed if five or more of the nine criteria of depression have been elicited more than half of the days in the past two weeks and one of the symptoms is depressed mood or anhedonia [13]. PHQ-9 severity score from 0 to 27 , since each item of the nine items can be scored from 0-3. (Not at all=0, nearly every day=3) [18].

\section{Statistical analysis}

Analysis and processing of data was done using the SPSS version 20 software IBM system. Frequency and percentages were used. Depression prevalence was calculated. $P$ value of $<0.05$ was considered for statistical significant.

\section{Definition of variables}

The independent variables evaluated to explain depression were Sociodemographic and clinical data include; age, gender, marital status, occupation, education, family history of mental illness, traumatic life events, and medical comorbidity. PHQ-9 used for evaluation and assessment of depression.

\section{Ethical issues}

After clarifying the aims of this study, informed consent and agreement were getting from each patient. Interviews were carried out with full privacy. Names and other details were kept anonymous.

\section{Results}

The current study includes total 52 diffuse idiopathic skeletal hyperostosis (DISH) patients. Nine of them not complete the questionnaire and withdrawn from the study. Data analysis was done for 43 patients. The age range was $45-80$ years, mean 58 \pm 9.6 years. About $80 \%$ fall into the age group $\geq 50$ years. Male was nearly three forth of the sample; $86 \%$ married, about $72 \%$ of higher education, $60 \%$ still active working, non-smokers $72 \%$. Patients with DISH exposed to life events $53.5 \%$, patients with family history positive of mental illness were $11.6 \%$, and about $35 \%$ have medical comorbidity (Table 1 ).

Duration of illness was 3-20 years, mean $8.5 \pm 4$ years. PHQ-9 range was $1-25$, mean $12.8 \pm 8.28$. The prevalence of depression among patients with DISH was $62.8 \%$; about $88.88 \%$ of moderate depression to severe depression (Table 2).

Depression was of significant correlation with age group $(P=0.020)$, gender $(P=0.042)$

Occupation ( $P=0.011)$, and life events $(P=0.004)$ (Table 3).

Table 1 Frequency and percentages of the sociodemographic and clinical characteristics of the patients with diffuse idiopathic skeletal hyperostosis (DISH) involve in the study.

\begin{tabular}{|c|c|c|c|}
\hline \multicolumn{2}{|c|}{ Characteristics } & No. & $\%$ \\
\hline \multirow{3}{*}{ Age Group } & below 50 years & 9 & 20.9 \\
\hline & $50-60$ years & 17 & 39.5 \\
\hline & above 60 years & 17 & 39.5 \\
\hline \multirow{2}{*}{ Gender } & Male & 33 & 76.7 \\
\hline & Female & 10 & 23.3 \\
\hline \multirow{2}{*}{ Marital Status } & Single & 6 & 14 \\
\hline & Married & 37 & 86 \\
\hline \multirow{3}{*}{ Education } & Intermediate & 12 & 27.9 \\
\hline & Secondary & 23 & 53.5 \\
\hline & College & 8 & 18.6 \\
\hline \multirow{5}{*}{ Occupation } & Unemployed & 12 & 27.9 \\
\hline & Free Work & 23 & 53.5 \\
\hline & Employed & 3 & 7.0 \\
\hline & Retired & 5 & 11.6 \\
\hline & Housekeeper & 6 & 14.0 \\
\hline \multirow{2}{*}{ Smoking } & non smoker & 31 & 72.1 \\
\hline & Smoker & 12 & 27.9 \\
\hline \multirow{2}{*}{ Life Events } & No & 20 & 46.5 \\
\hline & Yes & 23 & 53.5 \\
\hline \multirow{2}{*}{ Family History } & No & 38 & 88.4 \\
\hline & Yes & 5 & 11.6 \\
\hline \multirow{2}{*}{ Comorbidity } & No & 28 & 65.1 \\
\hline & Yes & 15 & 34.9 \\
\hline
\end{tabular}


Depression severity was correlated significantly with age group $(P=0.006)$ and life events $(P=0.014)$ (Table 4).

The correlation of depression was statistically significant with duration of illness $(P=0.030)$. The correlation of severity of depression was statistically significant with duration of illness $(\mathrm{P}=0.023)$ (Table 5).

\section{Discussion}

This is the first study explores depression among diffuse idiopathic skeletal hyperostosis (DISH) patients. The prevalence of depression among patients with diffuse idiopathic skeletal hyperostosis (DISH) was $62.8 \%$. Depression was of significant correlation with age group $(P=0.020)$, gender $(P=0.042)$, Occupation ( $P=0.011)$, and life events $(P=0.004)$. High severity of depression was found; about $88.88 \%$ of moderate to severe depression. Depression was significantly correlated with duration of illness $(P=0.030)$. Severity of depression was significantly correlated with duration of illness $(P=0.023)$. Up to the knowledge of the author there are no exact figures to compare the results of this study with it. Chronic physical disorders consider as one of the traumatic stressful life events that may precipitate depression and other psychological disorders.

The mechanisms behind physical disorders elevate the risk of initiation of depressive disorder were two mechanisms. The first has cognitive or psychological mechanism. Chronic difficulty or life events may induce depressive disorder in susceptible patients. Second mechanism, more specific relation appears

Table 3 Correlation of depression with sociodemographic and clinical characteristics of patients with diffuse idiopathic skeletal hyperostosis (DISH) involved in this study

\begin{tabular}{|c|c|c|c|c|}
\hline \multicolumn{2}{|c|}{$\begin{array}{c}\text { Sociodemographic and clinical } \\
\text { variables }\end{array}$} & $\begin{array}{c}\text { Not } \\
\text { depressed }\end{array}$ & Depressed & $\mathbf{P}$ \\
\hline \multirow{3}{*}{ Age Group } & below 50 years & 5 & 4 & \multirow{3}{*}{0.020} \\
\hline & $50-60$ years & 9 & 8 & \\
\hline & above 60 years & 2 & 15 & \\
\hline \multirow{2}{*}{ Gender } & Male & 15 & 18 & \multirow{2}{*}{0.042} \\
\hline & Female & 1 & 9 & \\
\hline \multirow{2}{*}{ Marital Status } & Single & 4 & 2 & \multirow{2}{*}{0.108} \\
\hline & Married & 12 & 25 & \\
\hline \multirow{3}{*}{ Education } & Intermediate & 5 & 7 & \multirow{3}{*}{0.573} \\
\hline & Secondary & 7 & 16 & \\
\hline & College & 4 & 4 & \\
\hline \multirow{4}{*}{ Occupation } & Unemployed & 1 & 11 & \multirow{4}{*}{0.011} \\
\hline & Free Work & 11 & 12 & \\
\hline & Employed & 3 & 0 & \\
\hline & Retired & 1 & 4 & \\
\hline \multirow{2}{*}{ Smoking } & non smoker & 12 & 19 & \multirow{2}{*}{0.744} \\
\hline & Smoker & 4 & 8 & \\
\hline \multirow{2}{*}{ Life Events } & No & 12 & 8 & \multirow{2}{*}{0.004} \\
\hline & Yes & 4 & 19 & \\
\hline \multirow{2}{*}{ Family History } & No & 15 & 23 & \multirow{2}{*}{0.397} \\
\hline & Yes & 1 & 4 & \\
\hline \multirow{2}{*}{ Comorbidity } & No & 13 & 15 & \multirow{2}{*}{0.087} \\
\hline & Yes & 3 & 12 & \\
\hline
\end{tabular}

$\mathrm{P}<0.05$ was considered statistically significant
Table 4 correlation of severity of depression with sociodemographic and clinical characteristics of patients with diffuse idiopathic skeletal hyperostosis (DISH) involved in this study.

\begin{tabular}{|c|c|c|c|c|c|c|}
\hline \multicolumn{2}{|c|}{$\begin{array}{c}\text { Sociodemographic and clinical } \\
\text { variables }\end{array}$} & \multirow{2}{*}{ 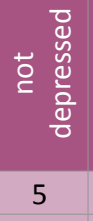 } & \multirow{2}{*}{ 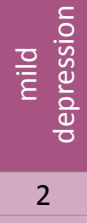 } & \multirow{2}{*}{ 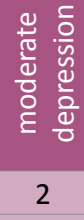 } & \multirow{2}{*}{ 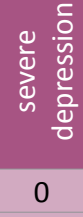 } & \multirow{4}{*}{$\begin{array}{l}\text { P value } \\
\mathbf{0 . 0 0 6}\end{array}$} \\
\hline \multirow{3}{*}{ Age Group } & below 50 years & & & & & \\
\hline & $50-60$ years & 9 & 0 & 6 & 2 & \\
\hline & above 60 years & 2 & 1 & 5 & 9 & \\
\hline \multirow{2}{*}{ Gender } & Male & 15 & 2 & 9 & 7 & \multirow{2}{*}{0.237} \\
\hline & Female & 1 & 1 & 4 & 4 & \\
\hline \multirow{2}{*}{ Marital Status } & Single & 4 & 1 & 0 & 1 & \multirow{2}{*}{0.180} \\
\hline & Married & 12 & 2 & 13 & 10 & \\
\hline \multirow{3}{*}{ Education } & Intermediate & 5 & 1 & 4 & 2 & \multirow{3}{*}{0.819} \\
\hline & Secondary & 7 & 1 & 8 & 7 & \\
\hline & College & 4 & 1 & 1 & 2 & \\
\hline \multirow{4}{*}{ Occupation } & Unemployed & 1 & 2 & 4 & 5 & \multirow{4}{*}{0.106} \\
\hline & Free Work & 11 & 1 & 6 & 5 & \\
\hline & Employed & 3 & 0 & 0 & 0 & \\
\hline & Retired & 1 & 0 & 3 & 1 & \\
\hline \multirow{2}{*}{ Smoking } & not smoker & 12 & 1 & 8 & 10 & \multirow{2}{*}{0.175} \\
\hline & Smoker & 4 & 2 & 5 & 1 & \\
\hline \multirow{2}{*}{ Life Events } & No & 12 & 2 & 4 & 2 & \multirow{2}{*}{0.014} \\
\hline & Yes & 4 & 1 & 9 & 9 & \\
\hline \multirow{2}{*}{ Family History } & No & 15 & 3 & 11 & 9 & \multirow{2}{*}{0.686} \\
\hline & Yes & 1 & 0 & 2 & 2 & \\
\hline \multirow{2}{*}{ Comorbidity } & No & 13 & 2 & 8 & 5 & \multirow{2}{*}{0.286} \\
\hline & Yes & 3 & 1 & 5 & 6 & \\
\hline
\end{tabular}

$\mathrm{P}<0.05$ was considered statistically significant

Table 5 Correlation of duration of illness with depression and severity of depression of patients with diffuse idiopathic skeletal hyperostosis (DISH) involved in this study.

\begin{tabular}{|c|c|c|c|c|c|c|}
\hline \multirow{2}{*}{\multicolumn{2}{|c|}{ severity of depression }} & \multicolumn{4}{|c|}{ Duration of illness } & \multirow[b]{2}{*}{ P value } \\
\hline & & \multirow{2}{*}{$\begin{array}{c}1-5 \\
\text { years } \\
5\end{array}$} & \multirow{2}{*}{$\begin{array}{c}6-10 \\
\text { years } \\
11\end{array}$} & \multirow{2}{*}{$\begin{array}{c}11-15 \\
\text { years } \\
0\end{array}$} & \multirow{2}{*}{$\begin{array}{c}16-20 \\
\text { years } \\
0\end{array}$} & \\
\hline \multirow[t]{2}{*}{ Depression } & $\begin{array}{c}\text { Not } \\
\text { depressed }\end{array}$ & & & & & \multirow[t]{2}{*}{0.030} \\
\hline & Depressed & 4 & 12 & 7 & 4 & \\
\hline \multirow{3}{*}{$\begin{array}{l}\text { Severity of } \\
\text { Depression }\end{array}$} & $\begin{array}{c}\text { mild } \\
\text { depression }\end{array}$ & 1 & 0 & 2 & 0 & \multirow{3}{*}{0.023} \\
\hline & $\begin{array}{l}\text { moderate } \\
\text { depression }\end{array}$ & 2 & 7 & 2 & 2 & \\
\hline & $\begin{array}{c}\text { severe } \\
\text { depression }\end{array}$ & 1 & 5 & 3 & 2 & \\
\hline
\end{tabular}

$\mathrm{P}<0.05$ was considered statistically significant

to present to link depression with certain physical illness [19]. Different variables have been identified in rheumatological disorders patients that of association with depressive disorder. Variables may include; physical disability degree, physical pain, disease duration, gender, social stress level and availability of social support [20-23]. Adaptation with severe or chronic physical disorders is difficult for the patients that may result in depression. Difficult adaptation may be due to changes social 
situation. Maladjustment in response to severe stress of medical disorder may results in depression7. Mental disorders form $12.1 \%$ of depression global burden and by the year 2020 are increase to $15 \%$. $25 \%$ of People may be affected during their lives by behavioural and mental disorders 23. People with chronic medical disorders are complaining of depressive disorder twice as compared with people without chronic illnesses [23,24]. There is association of depression with different disorders that presented with somatic or physical symptom, include, fibromyalgia, chronic fatigue and chronic pain states [19].

In conclusion depression is high in diffuse idiopathic skeletal hyperostosis (DISH) patients. Age, gender, occupation, life events, and duration of illness consider as the significant risk factors. Patients may get benefit from close liaison between mental health professionals and rheumatologist.

\section{References}

1 Mader R, Verlaan J-J, Eshed I, Jazome B-A, Puttini PS, et al.(2017) Diffuse idiopathic skeletal hyperostosis (DISH): where we are now and where to go next. RMD Open 3-e000472.

2 Goico-Alburquerque A, Zulfiqar B, Antoine R, Samee M (2017) Diffuse Idiopathic Skeletal Hyperostosis: Persistent Sore Throat and Dysphagia in an Elderly Smoker Male. Case Reports in Medicine 1:14.

3 Pulcherio JOB, Velasco CMMO, Machado RS, Souza WN, Menezes DR (2014) Forestier's disease and its implications in otolaryngology: literature review. Brazilian Journal of Otorhinolaryngology $80: 161-$ 166.

4 Mader R, Novofestovski I, Adawi M, Lavi I (2009) Metabolic syndrome and cardiovascular risk in patients with diffuse idiopathic skeletal hyperostosis. Seminar in arthritis and Rheumatism 38: 361-365.

5 Kim SK, Choi BR, Kim CG, Chung SH, Choe JY, et al. (2004) The prevalence of diffuse idiopathic skeletal hyperostosis in Korea. J Rheumato 31: 2032-2035.

6 Hiyama A, Katoh H, Sakai D, Sato M, Tanaka M, et al. (2018) Prevalence of diffuse idiopathic skeletal hyperostosis (DISH) assessed with whole spine computed tomography in 1479 subjects. BMC Musculoskelet Disord 19: 178.

7 Al Abbudi SJR (2018) Prevalence of symptoms of depression, anxiety and stress among secondary school students in Baghdad, Iraq International J Current Res 10: 66257.

8 Al Abbudi SJR, Ezzat KI, Farhan MS, Zebala AA, Al-Beedany MSJ, et al. (2017) Prevalence and determinants of depression among traumatic spinal cord injured patients attending Ibn-Al-Quff Hospital, Baghdad, Iraq. Iraqi J Med Sci 15: 383-395.

9 Zhao S, Thong D, Miller N, Duffield SJ, Hughes DM, et al. (2018) The prevalence of depression in axial spondyloarthritis and its association with disease activity: a systematic review and meta-analysis. Arthritis Res Therapy 20: 140 .

10 Adewuya AO, Ola BA, Afolabi OO (2006) Validity of the patient health questionnaire (PHQ-9) as a screening tool for depression amongst Nigerian university students. J Affect Disord 96: 89-93.

11 Spitzer RL, Kroenke K, Williams JBW, the Patient Health Questionnaire Primary Care Study Group (1999) Validation and utility of a selfreport version of PRIME-MD: The PHQ primary care study. Jama 282: 1737-1744.

12 Lee PW, Schulberg HC, Raue PJ, Kroenke K (2007) Concordance between the PHQ-9 and the HSCL-20 in depressed primary care patients. J Affect Disord 99: 139-145.

13 Kroenke K, Spitzer RL, Williams JBW (2001) The PHQ-9: validity of a brief depression severity measure. J Gen Intern Med 16: 606-613.

14 Lowe B, Schenkel I, Carney-Doebbeling C, Gobel C (2006) Responsiveness of the PHQ-9 to Psychopharmacological Depression Treatment. Psychosomatics 47: 62-67.

15 Pinto-Meza A, Serrano-Blanco A, Penarrubia MT, Blanco E, Haro JM (2005) Assessing depression in primary care with the PHQ-9: Can it be carried out over the telephone? J Gen Intern Med 20: 738-742.

16 Rief W, Nanke A, Klaiberg A, Braehler E (2004) Base rates for panic and depression according to the Brief Patient Health Questionnaire: A population-based study. J Affect Disord 82: 271-276.

17 AlHadi AN, AlAteeq DA, Al-Sharif E, Bawazeer HM, Alanazi $\mathrm{H}$, et al. (2017) An Arabic translation, reliability, and validation of Patient Health Questionnaire in a Saudi sample. Ann Gen Psychiatry 16:32.

18 Andreas JB, Brunborg GS (2017) Depressive Symptomatology among Norwegian Adolescent Boys and Girls: The Patient Health Questionnaire-9 (PHQ-9) Psychometric Properties and Correlates. Front Psychol 8: 887

19 Goodwin GM (2006) Depression and associated physical diseases and symptoms. Dialogues Clin Neurosci 8: 259-265.

20 Wolfe F, Hawley DJ (1993) The relationship between clinical activity and depression in rheumatoid arthritis. J Rheumatol 20: 2032-2037.

21 Katz PP, Yelin EH (1994) Life activities of persons with rheumatoid arthritis with and without depressive symptoms. Arthritis Care Res 7: 69-77.

22 Murphy S, Creed FH, Jayson MIV (1988) Psychiatric disorders and illness behaviour in rheumatoid arthritis. Rheumatol 27: 357-363.

23 Azad N, Gondal M, Abbas N (2008) Frequency of Depression and Anxiety in Patients Attending a Rheumatology Clinic. J Coll Physicians Surg Pak 18: 569-573.

24 Pattern SB (2001) Long-term medical conditions and major depression in a Canadian population study at waves 1 and 2. J Affect Disord 63: 35-41. 